\title{
Antecedent and consequences of organizational identification: a study in the tourism sector of Sikkim
}

\author{
Deepak Subba*
}

\begin{abstract}
Organizational identification has been identified as an important construct in behavioral research. It has been viewed from different perspectives such as marketing, organizational behavior, human resource management, and psychology. This study is conducted in organizational behavior context among the employees of tourism industry in Sikkim and gave some important contribution which can be useful to researchers and practitioners. With the application of social identity theory, the study investigated the antecedent and consequences of organizational identification. To test the research model, self-reports of 246 respondents are used and for analyzing data explorative factor analysis, confirmatory factor analysis and structural equation modeling were applied. Findings of the study suggested that perceived organizational support emerged as an antecedent of organizational identification, whereas job satisfaction and knowledge sharing behavior emerged as consequences of organizational identification.
\end{abstract}

\section{Introduction}

Over the last decades, in comparison with other psychological variables such as job satisfaction, ability and work motivation, organizational identification (OI) has garnered little attention from organizational psychologist. Although the first model of OI was proposed way back by March and Simon [28], there were limited studies which were published in this area in the following 20 years. In 1970s, Porter identified identification as a component of attitudinal organizational commitment. Since then, scholars have used the terms OI and affective organizational commitment interchangeably.

In the era of 1980s, researchers re-discovered OI as a unique construct in organizational behavior, communication and social psychology. The relevance of these social theories to organizational behavior context has been outlined by Ashforth and Mael [3]. The number of theoretical and empirical analyses focusing on organizational identification has increased significantly. In communication

*Correspondence: deepaksubba08@gmail.com

Department of Management, University of North Bengal, Siliguri, West Bengal 734013, India research, Cheney [7] investigated the relation of OI to control, communication and socialization.

A prestigious organization gives the opportunity to individuals to identify with them. Being associated with that organization can develop pride in members and lead to OI among them. Research demonstrates that individual factors are also important in increasing identification. Individual factors include tenure [34], collectivism [15], biodata [25], need for affiliation [49], and gender [23]. There are three broad areas of organizational identification outputs from the perspective of social identity theory [3]. Employees build their identities by aligning themselves with the organization. Secondly, outputs such as altruism, cohesion, positive evaluations and cooperation are affected by organizational identification. Lastly, as OI becomes stronger in members the practices and values make an organization distinct.

There are numerous outputs of organizational identification which have been identified including job satisfaction, in-role and extra-role behavior [34], financial contribution [27], turnover and intent to turnover [45], compliance with organizational norms [43], hours worked [31] intrinsic motivation and task performance [46], coordination and decision making [7], alienation, 
performance effectiveness and task involvement [11] defending the organization [10].

There exists a numerous supported relationships with organizational identification, but some important aspects have remained unanswered. However, recent research has looked at the relationship of OI with knowledge sharing behavior (KSB) [14], perceived organizational support (POS) [13] and job satisfaction [9]. To the best of researcher's knowledge, there is no such study where all these constructs have been included and tested empirically. We have developed a new model and tested on the employees of tourism industry in Sikkim.

\section{Literature review}

\section{Organizational identification}

It is defined as "the perception of belongingness or oneness to an organization, where individual defines him or herself in terms of an organization in which he or she is a member" [27]. Individuals who have strong OI see the success and failure of the organization in their own image and develop the feeling of belongingness with the organization. If organization is insulted, individuals take it personally and feel as if they were insulted. The distinctiveness of an organization's practices and values makes organizations unique which in turn lead an individual to identify with the organization. This was tested by [27] among the alumni of college. They found that the distinctiveness enhanced identification with the organization. Thus, a person who works for organizations which is distinct in some manner from comparable organizations is more likely to identify with their organizations.

\section{Perceived organizational support}

POS is the belief of individuals that employer is concerned about their well-being and values their contributions [12]. It provides some important information to employees regarding their relationship with the employer. A person who feels that he or she is integrated with other members of the organization is likely to presume that others view him or her as member of organization and therefore may more likely to view him or her as members of organization. Thus, perceived organizational support is important factor in reinforcing organizational outputs. POS was positively associated with related outputs including reward expectancies [12], affective organizational commitment [37], measures of job performance [12], influence techniques designed by employees to make manager aware of their achievement [38] and valuable inputs to employees [12], help coworkers [48]. POS was disassociated with negative outputs such as turnover intention [16] and absenteeism [12].

\section{Job satisfaction (JS)}

Since long time it has been identified as a critical construct in the study of organizational behavior. Since 1930 many attempts have been made by scholars to study it. Spector [39] defined Job satisfaction as "an attitudinal variable that reflects how people feel about their jobs overall as well as about various aspects of them". Locke [22] defined it as "a pleasurable or positive emotional state resulting from the appraisal of one's job or job experiences". Although job satisfaction is multi-dimensional construct, its definitions are concerned only with affective component [5]. Job satisfaction is associated with huge number of important constructs, including lateness [8] and job characteristics [47] AND well-being [35].

\section{Knowledge sharing behavior}

Knowledge sharing behavior refers to "behavior by which an individual voluntarily provides other social actors (both within and outside the organization) with access to his or her unique knowledge and experiences" [18]. There are two facets of KSB. They are

- Knowledge sharing is voluntary.

- Knowledge sharing takes place between people and is different from knowledge transfer which takes place between organizational entities.

KSB is categorized into four groups namely:

- Types of knowledge.

- Opportunity to share.

- Culture of the work environment.

- Motivation to share.

With respect to type of knowledge, explicit knowledge is easily transferable than tacit knowledge. Information and communications technology are used to share knowledge. Researchers reported that dimensions of culture such as organizational justice, communication and climate influence KSB. Factors such as self-efficacy, helping others, enjoyment motivates to share knowledge. There are numerous empirical studies which have identified the relationship of KSB with other constructs including OI [14], organizational commitment [30], organizational citizenship behavior [29].

\section{Hypotheses development POS and $O I$}

If employees perceive that employer cares about their well-being and values their contributions, then employees perceive high levels of support from employer. If employees perceive high levels of POS, then they tend 
to perceive that they are being respected, included and valued by employer, leading to high level of self-enhancement among them [24]. Employees who perceive selfenhancement are more instigated to identify with their organization. According to Organizational support and Social exchange theories, employees who perceive high level of support in the workplace are inclined to pay back to the organization. If employees perceive exchange relationship with the organization, then they strongly identify with the organization. Prior research has found that POS is an important contributor to organizational identification. POS affects the level of attachment to the organization [12]. Therefore, we anticipate that

H1 POS influences organizational identification.

\section{Organizational identification and knowledge sharing behavior}

The primary question in recent years is how organization achieves and sustains competitive advantage. In this regard, knowledge sharing is an important source of competitive advantage for the organization [20]. Some employees have fear of losing power, so they are reluctant to share knowledge in the workplace. Organizational identification induces knowledge sharing behavior among members by creating perceptions of belongingness and oneness to an organization. Organizational identification enhances pro-social behavior among members in the workplace by building a sense of a common fate and enhances cooperation among the members in the workplace. Members' consideration of mutual cooperation and benefit to the organization encourages them to share knowledge in the workplace [14]. Thus, we anticipate that employees who have strong identification with their organization intend to share knowledge with their members in the workplace.

H2 Organizational identification influences knowledge sharing behavior.

\section{Organizational identification influences job satisfaction}

Employees who identify with the organization are likely to attach with their organization. These employees demonstrate supportive behavior in the workplace [36]. They define their responsibilities and engage themselves in the activities which benefit the organization. Prior research has demonstrated that identification improves commitment, motivation and job satisfaction and reduces conflict and turnover [33, 45]. Identification prevents employees from being disoriented and enhances job satisfaction [6]. Job satisfaction is driven affectively and cognitively driven. Thus, affective and cognitive dimensions of identification are associated with job satisfaction. Strong identification enhances job satisfaction [26]. Thus, we anticipate that employees who have strong identification with their organization perceive higher job satisfaction.

\section{H3 Organizational identification influences job} satisfaction.

\section{Conceptual framework}

The social identity theory (SIT) proposed by Tajfel [40] is applicable to see the mediating effect of $\mathrm{OI}$ in two aspects

- First, in the relationship of POS and job satisfaction.

- Secondly, in the relationship of POS and knowledge sharing behavior.

The theory deals with relationship among groups and enables groups to make comparisons. As per the definition, social identity is self-concept that comes from membership and knowledge of groups together with the emotional attachment and value. It suggests that individuals classify themselves into specific groups through social comparisons to create distinctiveness [41]. It assumes that POS have a directly influences OI. Individuals strive to attain or sustain a positive social identity [1], which can be derived by becoming a member in classifying groups [3]. Membership in organizations is one of the important components among these classifying groups [19]. Researcher, e.g., Tyler [42] hinted that individuals use the social standing of their employer to assess their self-worth. They prefer to identify with firms which are prestigious and develop the self-worth and fulfill need for self-enhancement of their employees [41]. OI thus derives from the prestige and image of the organization [44]. Employees' assessment of the degree of respect with which the firms treats them influences identification [44].

In this context, POS may create positive distinctiveness among group members as it is associated with reputation of organization [4]. Firms must ensure the well-being of their employees. This well-being includes:

- Organizational justice.

- Career growth.

- Safety.

- Job security.

- Union relations.

- Family-friendly relations.

If employees perceive that they are being supported by their employer in all spheres of their life, then image of 


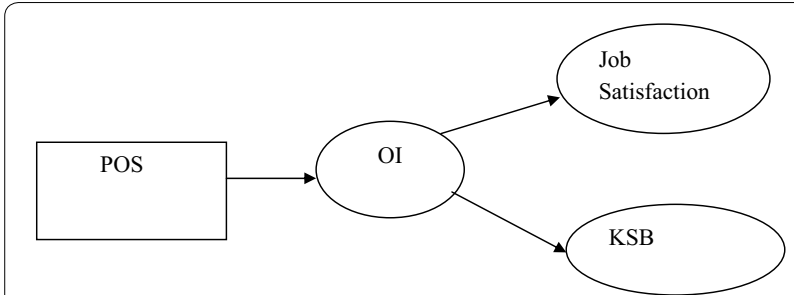

Fig. 1 Proposed conceptual framework

firms get enhanced in the mindset of employees which increases the willingness of these employees to identify with their firms and display work related outcome. Hence, POS can enhance individuals OI, which in turn affects their job satisfaction and KSB. Based on this analysis, a conceptual framework (see Fig. 1) and two mediating hypotheses are framed:

- H4 OI mediates the relationship between POS and job satisfaction.

- H5 OI mediates the relationship between POS and KSB.

\section{Methods}

To test the conceptual framework, a survey was conducted in the month of January to March 2017. Industries which come under tourism located in Sikkim were chosen for the study. The researcher sought permission from the in charge of the office and questionnaires were distributed to the employees. To reduce biasness, the employees were informed that their responses would remain confidential and used only for academic purpose. A total of 246 samples were collected by using convenience sampling. All the questionnaires were filled up properly by respondents and gave a response rate of $100 \%$. There were no missing values. The researcher used existing scale in the study. For example, instruments for POS were adapted from Eisenberger, [12], OI from Mael and Ashforth [27], job satisfaction from Agho et al. [2] and KSB from Lin [21]. The researchers pretested the instrument, and used five point Likert scales $(1=$ "strongly disagree" to $5=$ "strongly agree"). Since the Cronbach's alpha of two items of POS were less than cutoff criterion, i.e., 0.7 [17], hence deleted for further analysis. The proportion of male and female was $56.5 \%$ and $43.5 \%$, respectively. A majority of the respondents $(41.5 \%)$ were graduates, followed by diploma holders (40.7), post graduates (15.9) and Ph.D. which was just $2 \%$. In terms of age, $41.1 \%$ were aged $20-29,50.4 \%$ were aged $30-39,6.1 \%$ were aged $40-49$ and $2.4 \%$ were above 50 years. In terms of experience $40.7 \%$ had $0-5$ years, $33.3 \%$ had $5-10$, $15.4 \%$ had $10-15$ and 11 had more than 15 years.

\section{Data analysis \\ Descriptive statistics}

Table 1 displays means, standard deviation and correlations among constructs. The mean of $\mathrm{OI}$ is 4.26 which is the highest among all constructs and indicates high level of OI among employees of tourism industry in Sikkim. The means of other constructs ranges from 3.65 to 4.02 . The correlations among the construct are significant at $(p<0.01)$. POS is positively associated with OI, OI is positively associated with job satisfaction and KSB. The highest correlation is found between POS and job satisfaction.

\section{Common method variance (CMV)}

CMV leads to measurement error [32]. CMV can either deflate or inflate relationships among constructs, thus leads to measurement error, i.e., Type 1 and Type II. There are two approaches to check CMB, Harman's one factor and common latent factor. In Harman's one factor approach all items measuring constructs are loaded into one factor and run the EFA. If total variance for one factor is more than $50 \%$ then it poses a threat of CMV [17]. EFA with unrotated principal components analysis was run where all the variables were entered and constrained the number of factors to one. The single factor revealed $29.19 \%$. In common latent factor approach all the constructs are combined into one factor and run the CFA. If the measurement model displays satisfactory model it poses a threat of CMV [17]. CFA singlefactor model did not display the satisfactory model $\left[x^{2} / d f=2270.860 / 245=9.269\right.$, CFI (Comparative fit index $)=0.523$, TLI (Tucker Lewis index $)=462$, RMSEA $($ root square mean $)=0.18]$. Hence, it is confirmed by theses approaches that it doesn't pose a threat of common method bias.

\section{Exploratory factor analysis (EFA)}

EFA was performed to see the uni-dimensionality of the constructs and drop the instruments having low factor loading. EFA with unrotated PCA was run where all the

Table 1 Correlations, mean and standard deviation

\begin{tabular}{lllll}
\hline & POS & OI & Job satisfaction & KSB \\
\hline POS & 1 & & & \\
OI & $0.214^{* *}$ & 1 & & \\
Job satisfaction & $0.469^{* *}$ & $0.373^{* *}$ & 1 & 1 \\
KSB & $0.180^{* *}$ & $0.403^{* *}$ & $0.363^{* *}$ & 4.02 \\
Mean & 3.65 & 4.26 & 3.71 & 0.52 \\
Standard deviation & 0.59 & 0.57 & 0.64 & \\
\hline
\end{tabular}

${ }^{* *}$ Correlation is significant at the 0.01 level (2-tailed) 
variables were entered and constrain the number of factors to four. Analysis displayed seven distinct factors with eigenvalues $>1.0$ which were extracted to form a factor structure. Tables 2 and 3 represent the result of PCA. The Bartlett test of sphericity is significant, and value of (Kaiser-Meyer-Olkin) KMO is greater than cutoff criterion, i.e., 0.50 . The factor loadings of 24 items were above 0.4 and hence used all the items for further analysis. Hence, not even a single item was dropped.

\section{Confirmatory factor analysis (CFA)}

CFA was performed to check the measurement model presented in Table 4. One items from each construct were deleted for further analysis due to low factor loadings, remaining items had above the acceptable level of 0.7 [17]. Hence, these items were carried out for further analysis. The measurement model displayed a satisfactory level of fit $\left(x^{2} / d f=1155.210 / 253=4.57\right.$, $\mathrm{TLI}=0.91, \mathrm{CFI}=0.90, \mathrm{RMSEA}=0.07)$. The values of $\mathrm{CR}$ (composite reliability) were above 0.7 and greater than the values of AVE, and values of AVE (average variance extracted) were above 0.5 [17]; hence, convergent validity was established. In terms of discriminant validity, the values of average variance extracted were greater than the values of MSV (maximum shared variance) and ASV (average shared variance); hence, discriminant validity was established. Results of CFA is presented in Table 4, discriminant validity in Table 5 and mediation effects in Table 6.

\section{Structural equation modeling (SEM)}

SEM displayed a satisfactory level of fit $\left(x^{2} / d f=1201.68 / 289=4.15, \quad\right.$ TLI $=0.91, \quad$ CFI $=0.92$, RMSEA $=0.08$. The path estimates of the SEM are presented in Fig. 2 significant at $(p<0.01)$; thus, $\mathrm{H} 1, \mathrm{H} 2$, and $\mathrm{H} 3$ were accepted. To check the mediating role of OI, bootstrapping was performed. The standardized direct effect of POS on job satisfaction is 0.238 , insignificant
Table 3 Factor loadings, cumulative variance and KMO

\begin{tabular}{|c|c|c|c|c|}
\hline Constructs & Items & Factor loadings & $\begin{array}{l}\text { Cumulative } \\
\text { variance } \\
\text { explained (\%) }\end{array}$ & KMO \\
\hline \multirow[t]{6}{*}{ POS } & POS1 & 0.702 & 29.19 & 0.618 \\
\hline & POS2 & 0.822 & & \\
\hline & POS3 & 0.701 & & \\
\hline & POS4 & 0.765 & & \\
\hline & POS5 & 0.708 & & \\
\hline & POS6 & 0.701 & & \\
\hline \multirow[t]{5}{*}{ Ol } & Ol1 & 0.706 & 42.43 & \\
\hline & $\mathrm{Ol} 2$ & 0.843 & & \\
\hline & $\mathrm{Ol3}$ & 0.852 & & \\
\hline & $\mathrm{Ol} 4$ & 0.808 & & \\
\hline & Ol5 & 0.995 & & \\
\hline \multirow[t]{6}{*}{ Job satisfaction } & JS1 & 0.747 & 50.92 & \\
\hline & JS2 & 0.779 & & \\
\hline & JS3 & 0.772 & & \\
\hline & JS4 & 0.772 & & \\
\hline & JS5 & 0.755 & & \\
\hline & JS6 & 0.821 & & \\
\hline \multirow[t]{7}{*}{ KSB } & KSB1 & 0.874 & 59.10 & \\
\hline & KSB2 & 0.866 & & \\
\hline & KSB3 & 0.858 & & \\
\hline & KSB4 & 0.792 & & \\
\hline & KSB5 & 0.662 & & \\
\hline & KSB6 & 0.519 & & \\
\hline & KSB7 & 0.807 & & \\
\hline
\end{tabular}

$(p>0.05)$. The standardized indirect effect of POS on job satisfaction is 0.032 , significant $(p<0.05)$. Thus, it is evident that OI acts as a full mediator between POS and job satisfaction. The upper and lower bound values of the indirect effect of OI at $95 \%$ confidence interval are 0.089 and 0.019. The standardized direct effect of POS on KSB is 0.517 , significant $(p<0.05)$. The standardized indirect

Table 2 Principal component analysis (PCA)

\begin{tabular}{|c|c|c|c|c|c|c|}
\hline \multirow[t]{3}{*}{ Component } & \multicolumn{6}{|c|}{ Total variance explained } \\
\hline & \multicolumn{3}{|c|}{ Initial eigenvalues } & \multicolumn{3}{|c|}{ Extraction sums of squared loadings } \\
\hline & Total & $\%$ of Variance & Cumulative \% & Total & $\%$ of Variance & Cumulative \% \\
\hline 1 & 7.007 & 29.197 & 29.197 & 7.007 & 29.197 & 29.197 \\
\hline 2 & 3.178 & 13.242 & 42.439 & 3.178 & 13.242 & 42.439 \\
\hline 3 & 2.037 & 8.488 & 50.927 & 2.037 & 8.488 & 50.927 \\
\hline 4 & 1.963 & 8.178 & 59.105 & 1.963 & 8.178 & 59.105 \\
\hline 5 & 1.414 & 5.891 & 64.996 & 1.414 & 5.891 & 64.996 \\
\hline 6 & 1.267 & 5.281 & 70.277 & 1.267 & 5.281 & 70.277 \\
\hline 7 & 1.013 & 4.219 & 74.496 & 1.013 & 4.219 & 74.496 \\
\hline
\end{tabular}


Table 4 CFA analysis

\begin{tabular}{|c|c|c|c|c|}
\hline Constructs & Instruments & $\begin{array}{l}\text { Standardized } \\
\text { factor loading }\end{array}$ & AVE & CR \\
\hline \multirow[t]{6}{*}{ POS } & & & 0.614 & 0.779 \\
\hline & POS1 & 0.797 & & \\
\hline & POS2 & 0.822 & & \\
\hline & POS3 & 0.701 & & \\
\hline & POS4 & 0.765 & & \\
\hline & POS5 & 0.708 & & \\
\hline \multirow[t]{5}{*}{$\mathrm{Ol}$} & & & 0.555 & 0.762 \\
\hline & Ol1 & 0.995 & & \\
\hline & $\mathrm{Ol} 2$ & 0.843 & & \\
\hline & $\mathrm{Ol3}$ & 0.706 & & \\
\hline & $\mathrm{Ol4}$ & 0.701 & & \\
\hline \multirow[t]{6}{*}{ Job satisfaction } & & & 0.539 & 0.801 \\
\hline & Job Satisfaction 1 & 0.747 & & \\
\hline & Job Satisfaction2 & 0.779 & & \\
\hline & Job Satisfaction3 & 0.772 & & \\
\hline & Job Satisfaction4 & 0.755 & & \\
\hline & Job Satisfaction5 & 0.821 & & \\
\hline \multirow[t]{7}{*}{ KSB } & & & 0.638 & 0.872 \\
\hline & KSB1 & 0.916 & & \\
\hline & KSB2 & 0.884 & & \\
\hline & KSB3 & 0.723 & & \\
\hline & KSB4 & 0.757 & & \\
\hline & KSB5 & 0.700 & & \\
\hline & KSB6 & 0.724 & & \\
\hline
\end{tabular}

effect of POS on KSB is 0.393 , significant $(p<0.05)$. The upper and lower bound values of the indirect effect of OI at $95 \%$ are 0.099 and 0.022 . Thus, it is evident that OI act as a partial mediator between POS and KSB. Hence, H4 was fully and $\mathrm{H} 5$ was partially supported.

\section{Discussion}

The motivation behind this research emerges due to the dearth of studies conducted in the domain of OI which focuses its antecedents and consequences in Indian context. This research explains how POS induces OI which in turn displays work related outcomes such as KSB and JS. On the basis of the literature, a framework is conceptualized and developed five hypotheses:

- POS influences OI.

- OI influences JS.

- OI influences KSB.

- OI mediates the relationship between POS and JS.

- OI mediates the relationship between POS and KSB.

These hypotheses were tested and found that all the hypotheses were accepted. The first hypothesis, POS influences $\mathrm{OI}$ is coincided with prior study [13] who generated the similar finding. Similarly, second and third hypotheses OI influences JS and KSB generated findings which are coincided with prior studies [9]. The fourth hypothesis which anticipates that OI mediates the relationship between POS and JS is fully accepted. Lastly, fifth hypothesis which anticipates that OI mediates the relationship between POS and KSB is partially accepted. These mediating effects are tested by bootstrapping techniques.

All the constructs used in current study were measured by existing scales. The reliability of the items was checked by performing pilot study, and uni-dimensionality of constructs was checked by performing EFA. Conceptualized

Table 5 Discriminant validity analysis

\begin{tabular}{llllllll}
\hline & CR & AVE & MSV & ASV & JS & PSB \\
\hline JS & 0.864 & 0.614 & 0.303 & 0.246 & 0.783 & \\
POS & 0.831 & 0.555 & 0.303 & 0.124 & 0.550 & 0.745 \\
OI & 0.773 & 0.539 & 0.240 & 0.130 & 0.490 & 0.085 \\
KSB & 0.874 & 0.638 & 0.194 & 0.133 & 0.441 & 0.247 \\
\hline
\end{tabular}

Table 6 Mediation effects analysis

\begin{tabular}{llll}
\hline Hypotheses & Direct effects & Indirect effects & Comments \\
\hline $\mathrm{POS} \rightarrow \mathrm{Ol} \rightarrow$ Job satisfaction & 0.238 & $0.032^{*}$ & Full mediation \\
$\mathrm{POS} \rightarrow \mathrm{Ol} \rightarrow \mathrm{KSB}$ & $0.517^{*}$ & $0.038^{*}$ & Partial mediation \\
\hline${ }^{*} p<0.05$ & & &
\end{tabular}




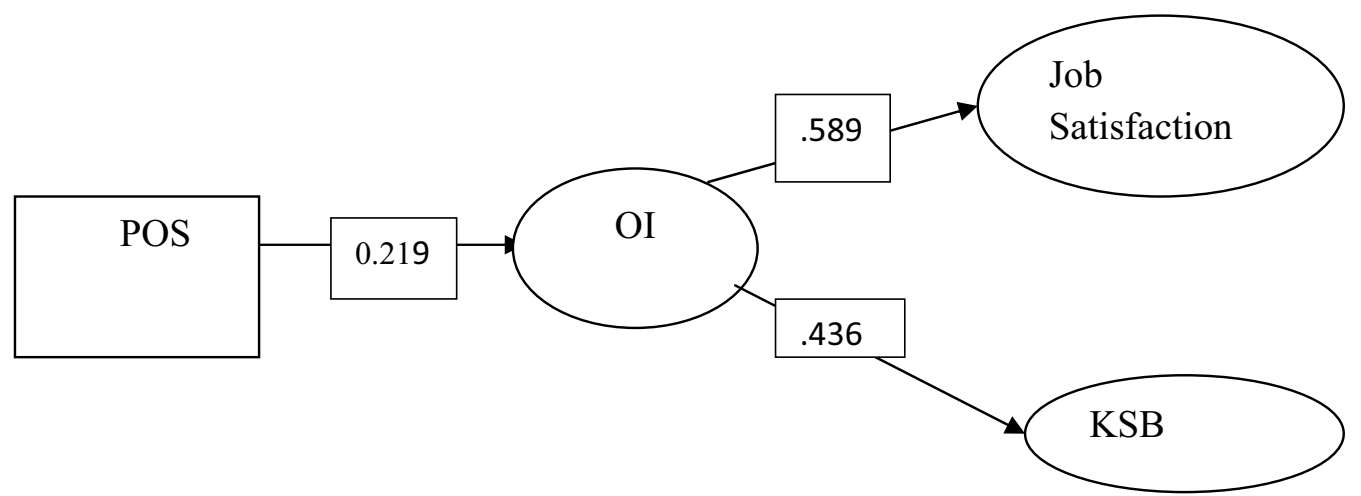

Fig. 2 Path estimates results for the proposed model

framework was measured and validated by CFA and SEM. SEM also displays multiple relationship and path estimates that exist among the constructs.

Some important findings were generated from the current study. Although tourism industry is dominated by males which constitutes $53.4 \%$, the number of females was also good which constitutes $43.5 \%$ which are rare in other industries indicating that tourism industry is very successful in attracting women candidates. Most of the employees working in the industry were graduates and diploma holders as compared to postgraduates and Ph.D. holders indicating that highly qualified employees prefer to join other industries. Majority of the employees are young aged from 20 to 40 indicating that tourism industry is providing avenue for youth employment opportunities in the region. In terms of experience, only $11 \%$ are having more than 15 years of work experience indicating that employees take early retirement or switch to other industries.

\section{Implications}

\section{Theoretical implications}

Prior studies have focused on how POS influences OI [13] and how OI influences job satisfaction and KSB [9, 14], but till date there is no such study where all constructs have been included. The researcher fills this gap by conceptualizing the framework and tested and validated in Indian context.

Findings of the study suggest that POS influences OI, giving support to SIT. Findings indicate that if there is high degree of POS, then employees get emotionally connected and identify themselves with their organization.

Results of bootstrapping analysis support that OI act as a mediator between

- POS and job satisfaction.

- POS and KSB.
The partial and full mediation effect of OI indicates that POS prevailing in the workplace induce employees to identify which in turn put extra role behavior among employees.

\section{Practical implications}

This study gives series of recommendation to the managers of tourism industry to enhance the organizational identification among members which in turn improves the efficiency of the organization. The success of organization depends on the employees of an organization, and prior research has found that organizational identification is an important factor which helps organization to be more competitive and successful.

Sikkim has always been the center of attraction for the international tourist as well as domestic. Tourism is booming and generating lots of revenue to the government and also to the local people. This study may be very useful to the government for framing the effective plans and policies for the growth of tourism industry in that region.

To the best of researcher's knowledge, prior researcher has never addressed such research problem in the tourism industry of Sikkim which gives an important contribution to stream of research.

\section{Conclusion}

The limitation of study must be addressed in future investigation. The data were collected by using convenience sampling technique. Future investigation may consider alternative technique to establish generalizability. Although common method bias was checked by using Harman single-factor test, still there might be threat of common method bias because the data were collected from single source. The data were collected at single point of time which hinders researchers to establish causality; hence, a longitudinal design can be used 
in future investigation. Findings may vary due to difference in behavior pattern and operation in other countries and industries. Therefore, future investigation can be conducted in other countries and industries. Finally, other predictors and outcomes of OI could be included and proposed a new framework which has to be tested and validated empirically by future researchers. OI has been identified as an important construct in behavioral research. It has been viewed from different perspectives such as marketing, organizational behavior, human resource management, and psychology. This study is conducted in organizational behavior context among the employees of tourism industry in Sikkim and gave some important contribution which can be useful to researchers and practitioners.

\section{Abbreviations}

ASV: average shared variance; CFA: confirmatory factor analysis; CMB: common method bias; CMV: common method variance; CR: composite reliability; EFA: explorative factor analysis; JS: job satisfaction; KMO: Kaiser-Meyer-Olkin; KSB: knowledge sharing behavior; MSV: maximum shared variance; Ol: organizational identification; PCA: principal component analysis; POS: perceived organizational support; RMSEA: root square mean; SEM: structural equation modeling; TLI: Tucker Lewis index.

\section{Acknowledgements}

Not applicable.

\section{Authors' contributions}

DS is a single author of this study. The author read and approved the final manuscript.

\section{Funding}

No funding was obtained for this study.

\section{Availability of data and materials}

Data was collected from the employees of tourism sector in Sikkim.

\section{Competing interests}

The author declares that there are no competing interests.

Received: 2 August 2019 Accepted: 12 November 2019

Published online: 04 December 2019

\section{References}

1. Aberson CL, Healy M, Romero V (2000) Ingroup bias and self-esteem: a meta-analysis. Pers Soc Psychol Rev 4(2):157-173

2. Agho AO, Price JL, Mueller CW (1992) Discriminant validity of measures of job satisfaction, positive affectivity and negative affectivity. J Occup Organ Psychol 65(3):185-195

3. Ashforth BE, Mael F (1989) Social identity theory and the organization. Acad Manag Rev 14(1):20-39

4. Branco MC, Rodrigues LL (2006) Corporate social responsibility and resource-based perspectives. J Bus Ethics 69(2):111-132

5. Brief AP (1998) Attitudes in and around organizations, vol 9. Sage, Newbury Park

6. Brunetto Y, Farr-Wharton R (2002) Using social identity theory to explain the job satisfaction of public sector employees. Int J Public Sector Manag 15(7):534-551

7. Cheney G (1983) On the various and changing meanings of organizational membership: a field study of organizational identification. Commun Monogr 50(4):342-362
8. Clark K, Peters SA, Tomlinson M (2005) The determinants of lateness: evidence from British workers. Scott J Polit Econ 52(2):282-304

9. De Roeck K, Marique G, Stinglhamber F, Swaen V (2014) Understanding employees' responses to corporate social responsibility: mediating roles of overall justice and organisational identification. Int J Hum Resour Manag 25(1):91-112

10. Edwards MR (2005) Organizational identification: a conceptual and operational review. Int J Manag Rev 7(4):207-230

11. Efraty D, Wolfe DM (1988) The effect of organizational identification on employee affective and performance responses. J Bus Psychol 3(1):105-112

12. Eisenberger M (1990) Chemotherapy for endocrine resistant cancer of the prostate. Prog Clin Biol Res 359:155-164

13. Ertürk A (2010) Exploring predictors of organizational identification: moderating role of trust on the associations between empowerment, organizational support, and identification. Eur J Work Organ Psychol 19(4):409-441

14. Farooq M, Farooq O, Jasimuddin SM (2014) Employees response to corporate social responsibility: exploring the role of employees' collectivist orientation. Eur Manag J 32(6):916-927

15. Gundlach M, Zivnuska S, Stoner J (2006) Understanding the relationship between individualism-collectivism and team performance through an integration of social identity theory and the social relations model. Hum Relat 59(12):1603-1632

16. Guzzo RA, Noonan KA (1994) Human resource practices as communications and the psychological contract. Hum Resour Manag 33(3):447-462

17. Hair JF, Anderson RE, Babin BJ, Black WC (2010) Multivariate data analysis: a global perspective, vol 7. Pearson, Upper Saddle River

18. Hansen S, Avital M (2005) Share and share alike: the social and technological influences on knowledge sharing behavior. Sprouts Work Pap Inf Environ Syst Organ 5(1):1-19

19. Hogg MA, Terry DI (2000) Social identity and self-categorization processes in organizational contexts. Acad Manag Rev 25(1):121-140

20. Jasimuddin SM (2007) Exploring knowledge transfer mechanisms: the case of a UK-based group within a high-tech global corporation. Int J Inf Manag 27(4):294-300

21. Lin HF (2007) Effects of extrinsic and intrinsic motivation on employee knowledge sharing intentions. J Inf Sci 33(2):135-149

22. Locke EA (1976) The nature and consequences of job satisfaction. In: Dunnette MD (ed) Handbook of industrial organization psychology. Rand McNally, Chicago

23. Lucas R (1997) Youth, gender and part-time work-students in the labour process. Work Employ Soc 11(4):595-614

24. Luhtanen R, Crocker J (1992) A collective self-esteem scale: self-evaluation of one's social identity. Pers Soc Psychol Bull 18(3):302-318

25. Mael FA, Ashforth BE (1995) Loyal from day one: biodata, organizational identification, and turnover among newcomers. Pers Psychol 48(2):309-333

26. Mael FA, Tetrick LE (1992) Identifying organizational identification. Educ Psychol Measur 52(4):813-824

27. Mael F, Ashforth BE (1992) Alumni and their alma mater: a partial test of the reformulated model of organizational identification. J Organ Behav 13(2):103-123

28. March JG, Simon HA (1958) Organizations. Wiley, New York

29. Mogotsi IC, Boon JA, Fletcher $L$ (2011) Modelling the relationships between knowledge sharing, organisational citizenship, job satisfaction and organisational commitment among school teachers in Botswana. Afr J Libr Arch Inf Sci 21(1):41-59

30. Muneer S, labal SMJ, Long CS (2014) An incorporated structure of perceived organizational support, knowledge-sharing behavior, organizational trust and organizational commitment: a strategic knowledge management approach. Pak J Commer Soc Sci 8(1):42-57

31. Ng TW, Feldman DC (2008) Long work hours: a social identity perspective on meta-analysis data. J Organ Behav 29(7):853-880

32. Podsakoff PM, MacKenzie SB, Lee JY, Podsakoff NP (2003) Common method biases in behavioral research: a critical review of the literature and recommended remedies. J Appl Psychol 88(5):879

33. Pratt MG (1998) Central questions in organizational identification. In: Identity in organizations, pp 171-207 
34. Riketta M (2005) Organizational identification: a meta-analysis. J Vocat Behav 66(2):358-384

35. Schmitt N, Pulakos ED (1985) Predicting job satisfaction from life satisfaction: is there a general satisfaction factor? Int J Psychol 20(2):155-167

36. Shamir B (1990) Calculations, values, and identities: the sources of collectivistic work motivation. Hum Relat 43(4):313-332

37. Shore LM, Tetrick LE (1991) A construct validity study of the survey of perceived organizational support. J Appl Psychol 76(5):637

38. Shore LM, Wayne SJ (1993) Commitment and employee behavior: comparison of affective commitment and continuance commitment with perceived organizational support. J Appl Psychol 78(5):774

39. Spector PE (1997) Job satisfaction: application, assessment, cause, and consequences. Sage Press, Thousand Oaks

40. Tajfel HE (1978) Differentiation between social groups: Studies in the social psychology of intergroup relations. Academic Press, Cambridge

41. Tajfel H, Turner JC (1978) An integrative theory of inter-group confict. The social psychology of intergroup relations, pp 33-47

42. Tyler TR (1999) Why people cooperate with organizations: an identitybased perspective. Res Organ Behav 21:201-246

43. Tyler TR, Blader SL (2001) Identity and cooperative behavior in groups. Group Process Intergroup Relat 4(3):207-226

44. Tyler TR, Blader SL (2003) The group engagement model: procedural justice, social identity, and cooperative behavior. Pers Soc Psychol Rev 7(4):349-361
45. Van Dick R, Christ O, Stellmacher J, Wagner U, Ahlswede O, Grubba C et al (2004) Should I stay or should I go? Explaining turnover intentions with organizational identification and job satisfaction. Br J Manag 15(4):351-360

46. Van Knippenberg D (2000) Work motivation and performance: a social identity perspective. Appl Psychol 49(3):357-371

47. Voydanoff $P(1980)$ Perceived job characteristics and job satisfaction among men and women. Psychol Women Q 5(2):177-185

48. Wayne SJ, Shore LM, Liden RC (1997) Perceived organizational support and leader-member exchange: a social exchange perspective. Acad Manag J 40(1):82-111

49. Wiesenfeld BM, Raghuram S, Garud R (2001) Organizational identification among virtual workers: the role of need for affiliation and perceived work-based social support. J Manag 27(2):213-229

\section{Publisher's Note}

Springer Nature remains neutral with regard to jurisdictional claims in published maps and institutional affiliations.

\section{Submit your manuscript to a SpringerOpen ${ }^{\circ}$ journal and benefit from:}

- Convenient online submission

- Rigorous peer review

- Open access: articles freely available online

- High visibility within the field

- Retaining the copyright to your article

Submit your next manuscript at $\boldsymbol{\nabla}$ springeropen.com 